\title{
DISTRIBUTION OF GENES ENCODING RESISTANCE TO MACROLIDES, LINCOSAMIDES, AND STREPTOGRAMINS AMONG METHICILLIN- RESISTANT STAPHYLOCOCCUS AUREUS STRAINS ISOLATED FROM BURN PATIENTS
}

\author{
SAEED KHOSHNOOD $^{1,2}$, FATEMEH SHAHI $^{1,3 *}$, NABI JOMEHZADEH ${ }^{4}$,

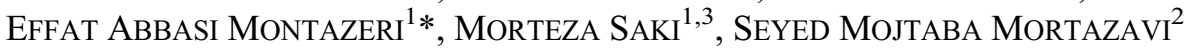 \\ and LEILA MAGHSOUMI-NOROUZABAD ${ }^{3,5}$ \\ ${ }^{1}$ Department of Microbiology, Faculty of Medicine, Ahvaz Jundishapur University of \\ Medical Sciences, Ahvaz, Iran \\ ${ }^{2}$ Student Research Committee, School of Medicine, Bam University of Medical Sciences, \\ Bam, Iran \\ ${ }^{3}$ Student Research Committee, Ahvaz Jundishapur University of Medical Sciences, \\ Ahvaz, Iran \\ ${ }^{4}$ Abadan School of Medical Sciences, Abadan, Iran \\ ${ }^{5}$ Nutrition and Metabolic Diseases Research Center, Ahvaz Jundishapur University of \\ Medical Sciences, Ahvaz, Iran
}

(Received: 7 February 2019; accepted: 11 March 2019)

The increasing resistance to macrolide, lincosamide, and streptogramin B agents among methicillin-resistant Staphylococcus aureus (MRSA) is a worldwide problem for the health community. This study aimed to investigate the prevalence of ermA, ermB, erm $C$, and msrA in MRSA strains isolated from burn patients in Ahvaz, southwest of Iran. A total of 76 isolates of S. aureus were collected from January to May 2017 from Taleghani Burn Hospital in Ahvaz. Among 76 S. aureus strains collected, 60 (78.9\%) isolates were MRSA. The antimicrobial susceptibility testing for MRSA showed extreme high resistance rate to clarithromycin $(100 \%)$ and azithromycin $(100 \%)$, followed by erythromycin (98.3\%). The PCR assay revealed that the frequency rates of $m s r A$, ermA, and $e r m C$ genes were 23 (38.3\%), 28 (46.7\%), and 22 (36.7\%), respectively. In addition, none of the MRSA isolates had the ermB gene. Because of the high prevalence of macrolide and lincosamide resistance found in MRSA isolates from infections of burn patients in Ahvaz, southwest of Iran, it is recommended that local periodic survey be performed for controlling the dissemination of antimicrobial resistance.

Keywords: Staphylococcus aureus, erm genes, MRSA, clindamycin, Iran

\footnotetext{
*Corresponding authors; E-mails: Shahiftm66@gmail.com; eam1043@gmail.com
} 


\section{Introduction}

Infection is the most serious complication among burned patients, which is difficult to control and remains to be the leading cause of morbidity and mortality in these patients. In addition, invasive infections caused by antibiotic-resistant bacteria, which are responsible for $28 \%-65 \%$ of burn deaths globally, should be considered as a potential risk and their resistance pattern must be identified as soon as possible $[1,2]$.

Staphylococcus aureus is known to be one of the most common burn wound pathogens worldwide. Colonization of $S$. aureus on the surface of burn wounds could be associated with delayed wound healing, increased treatment costs through the need for expensive antibiotics, prolonged duration of stay at burn centers, and increased need for surgical interventions [3, 4].

Since the discovery of the first effective antimicrobials in medical science, $S$. aureus has demonstrated rapid development of antibiotic resistance, as well as developed resistance to the most variety of antibiotics [5]. Although $\beta$-lactam antibiotics are the main compounds utilized to treat staphylococci-related infections, the emergence of methicillin-resistant $S$. aureus (MRSA) and alterations in antimicrobial resistance pattern has caused renewed interest in the use of antibiotics, such as macrolide, lincosamide, and streptogramin B (MLSB), for the treatment of these infections [6].

This group of antibiotics, in spite of their different chemical structure, has a similar mode of action and has been classified in the same group. They inhibit protein synthesis by binding to the subunit $23 \mathrm{~S}$ rRNA of the bacterial $50 \mathrm{~s}$ ribosomal subunits [7]. Among MLSB, clindamycin, due to its pharmacokinetic properties such as good oral absorption, excellent penetration in the skin, and tolerability, is a frequent choice for some staphylococcal infections, particularly skin and soft-tissue infections. However, extensive use of these antibiotics has led to the emergence of resistance to them [8].

Resistance to MLSB antibiotics among staphylococci more often involves the following two mechanisms, such as the active efflux of the antimicrobial agent by an ATP-dependent pump encoded by $m s r A$ gene and the ribosomal binding site modification by $23 \mathrm{~S}$ rRNA methylases mediated by one or more erm genes ( $\mathrm{erm} A$, erm $B$, erm $C$, and erm $F$ ) among which erm $A$ and erm $C$ are predominant genes [9].

Mechanism of ribosomal target site modification can be either constitutive or inducible. S. aureus isolates with constitutive resistance show resistance to erythromycin and clindamycin on in vitro testing, whereas isolates with inducible resistance show resistance to erythromycin but appear sensitive to clindamycin on disk diffusion testing [10,11]. The aim of this study was to investigate the molecular detection of MLSB resistance genes (ermA, ermB, ermC, mecA, and 
$m s r A$ ) and antibiotic resistance profiles in MRSA strains isolated from burn patients using polymerase chain reaction (PCR) technique in southwest Iran.

\section{Materials and Methods}

\section{Bacterial isolates}

In this cross-sectional study, clinical samples were collected from burn patients, admitted to the Taleghani Burn Hospital, Ahvaz, Iran, from January to May 2017. The research was approved by the ethical committee of Ahvaz Jundishapur University of Medical Sciences, Khuzestan, Iran. As a part of the Ahvaz Jundishapur University of Medical Sciences policy, written informed consent was obtained from all patients. The study was conducted in accordance with the Declaration of Helsinki. The specimens included were urine, blood, abscess, deep wound, and endotracheal secretion. The samples were cultured on $10 \%$ sheep blood agar and Mannitol salt agar (Merck, Darmstadt, Germany). Presumptive staphylococcal colonies (growth on mannitol salt agar, Grampositive, and catalase-positive cocci) were tested for production of DNase and coagulase. Isolates with positive reactions (DNase-positive and coagulasepositive) were considered as $S$. aureus [12].

\section{Cefoxitin and oxacillin disk diffusion method}

Susceptibility tests for $S$. aureus isolates were performed by the KirbyBauer disk diffusion method as recommended by Clinical and Laboratory Standards Institute (CLSI) using oxacillin $(1 \mu \mathrm{g})$ and cefoxitin $(30 \mu \mathrm{g})$ disks. The inhibition zones for the oxacillin disk with diameter $\leq 10 \mathrm{~mm}$ for $S$. aureus were considered to be resistant and the inhibition zone for cefoxitin with diameters of $\geq 20$ and $\leq 19 \mathrm{~mm}$ were considered susceptible and resistant, respectively [13].

\section{Epsilometer test}

The Epsilometer test (E-test) was conducted for quantitative antimicrobial susceptibility testing using E-test strips (Liofilchem, Italy). A standard bacterial suspension equal to $0.5 \mathrm{McF}$ arland inoculated on Mueller-Hinton agar (MHA) plates; then, E-test strips of tigecycline, linezolid, teicoplanin, vancomycin, and quinupristin/dalfopristin were placed on the medium surface and incubated at $35^{\circ} \mathrm{C}$ for $24 \mathrm{~h}$ for detection of minimum inhibitory concentration (MIC). The MIC was 
read at the lowest concentration at which the border of the elliptical inhibition zone intercepted the scale on the strip.

\section{Oxacillin-salt agar screening}

The presence of MRSA was confirmed by oxacillin-salt agar screening test. This test was performed according to CLSI recommendations [13]. For each isolate, $1 \mathrm{ml}$ of standard $0.5 \mathrm{McF}$ arland suspension was cultured on an MHA medium containing oxacillin (at a concentration of $6 \mu \mathrm{g} / \mathrm{ml}$ of media) and $4 \% \mathrm{NaCl}$. The plates were incubated in ambient air at $35{ }^{\circ} \mathrm{C}$ for $24 \mathrm{~h}$. Any growth on the plate was indicated as oxacillin resistance.

\section{MRSA antibiotic susceptibility pattern}

Susceptibility testing of MRSA isolates against erythromycin $(15 \mu \mathrm{g})$, clarithromycin $(15 \mu \mathrm{g})$, azithromycin $(15 \mu \mathrm{g})$, vancomycin $(30 \mu \mathrm{g})$, clindamycin $(2 \mu \mathrm{g})$, linezolid $(30 \mathrm{mg})$, teicoplanin $(30 \mu \mathrm{g})$, trimethoprim/sulfamethoxazole $(1.25 / 23.75 \mu \mathrm{g})$, quinupristin/dalfopristin $(15 \mu \mathrm{g})$, tigecycline $(15 \mu \mathrm{g})$, gentamicin $(10 \mu \mathrm{g})$, and rifampin (5 $\mu \mathrm{g})$ disks (Mast, Merseyside, United Kingdom) was determined by the Kirby-Bauer disk diffusion method on MHA, according to the procedures described by the CLSI guidelines. On following this, inducible clindamycin resistance was determined using the D-zone test according to these guidelines [13]. S. aureus ATCC 25923 was used as the reference strain.

Amplification of $16 \mathrm{~S}$ rRNA gene specific for $\mathrm{S}$. aureus and ermA, ermB, ermC, mecA, and msrA genes

DNA was extracted from bacterial colonies by the simple boiling method as previously described [4]. In brief, a few bacterial colonies were suspended in $400 \mathrm{ml}$ of tris ethylene diaminetetraacetic acid buffer $(\mathrm{pH} \mathrm{8.0)}$, and the solution was heated at $100{ }^{\circ} \mathrm{C}$ for $10 \mathrm{~min}$ and then centrifuged at $15,000 \mathrm{rpm}$ for $15 \mathrm{~min}$. The supernatant was used as template DNA in PCR.

The PCR assay was performed in $25 \mu$ contained a DNA template (50 ng), $100 \mu \mathrm{M}$ concentrations (each) of the four dNTPs, $1 \mathrm{U}$ of Taq DNA polymerase (Cinnagen, Iran), $5 \mu$ of Taq buffer $(5 \times), 25 \mathrm{pM}$ of each of forward and reverse primers ermA, ermB, ermC, and $m s r A$ (Table I). The PCR mixtures were subjected to thermal cycling $\left(4 \mathrm{~min}\right.$ at $94{ }^{\circ} \mathrm{C}$, followed by 30 cycles of $30 \mathrm{~s}$ at $94{ }^{\circ} \mathrm{C}$ for denaturation, $30 \mathrm{~s}$ for annealing extension, and extension at $72^{\circ} \mathrm{C}$ for $30 \mathrm{~s}$ ). A final elongation at $72{ }^{\circ} \mathrm{C}$ for $5 \mathrm{~min}$ was achieved in a DNA thermal cycler [14]. 
Table I. Primers and their target genes used in this study

\begin{tabular}{|c|c|c|c|}
\hline Primer & Sequence $\left(5^{\prime}-3^{\prime}\right)$ & Product size (bp) & Reference \\
\hline \multirow[t]{2}{*}{$16 S r R N A$} & F: GAA AGC GTG GGG ATC AAA CA & 340 & [15] \\
\hline & R: TTG CGG GAC TTA ACC CAA CA & & \\
\hline \multirow[t]{2}{*}{ ermA } & F: GAT TTC GTT CCT CGA CC & 139 & [15] \\
\hline & R: TAT CTT ATC GTT GAG AAG GGA TT & & \\
\hline \multirow[t]{2}{*}{$\operatorname{erm} B$} & F: CTA TCT GAT TGT TGA AGA AGG ATT & 142 & [15] \\
\hline & R: TTT ACT CTT GGT TTA GGA TGA AA & & \\
\hline \multirow[t]{2}{*}{ erm $C$} & F: CTT GTT GAT CAC GAT AAT TTC C & 190 & [15] \\
\hline & R: ATC TTT TAG CAA ACC CGT ATT C & & \\
\hline \multirow[t]{2}{*}{$m s r A$} & F: TCC AAT CAT TGC ACA AAA TC & 163 & [16] \\
\hline & R: AAT TCC CTC TAT TTG GTG GTC & & \\
\hline \multirow[t]{2}{*}{ mecA } & F: ACGGTAACATTGATCG-CAACG & 176 & [15] \\
\hline & R: GGCCAATTCCACATTGTTTCG & & \\
\hline
\end{tabular}

PCR products were analyzed by $1 \%$ agarose gel electrophoresis in $1 \times$ tris-borateEDTA buffer at $\mathrm{pH}$ 8.3. The amplification products were photographed and their size was determined using a 100-bp molecular size marker [14].

\section{Statistical analysis}

Descriptive data were analyzed using SPSS v.22.0 statistics software (IBM Corporation, Armonk, NY, USA). $\chi^{2}$ and $t$-tests were used to analyze intergroup significance. In addition, $p<0.05$ was considered statistically significant.

\section{Results}

\section{Bacterial isolates}

From the total screened samples during 6 months, $76 \mathrm{~S}$. aureus were isolated by biochemical tests and $16 S r R N A$ gene PCR. Using cefoxitin and oxacillin disk diffusion and oxacillin-salt agar screening and PCR for the mecA gene, 60 (79\%) of $S$. aureus were identified as being methicillin-resistant. Out of 60 MRSA isolates studied, $34(56.7 \%)$ and $26(43.3 \%)$ strains were collected from male and female patients, respectively. The sample sources according to the hospital wards were as follows: the internal women, internal men, pediatric, intensive care unit, and surgery, repair, and outpatient department (OPD), with proportions of $6(10 \%), 12(20 \%)$, $9(15 \%), 26(43.3 \%), 2(3.3 \%), 4(6.7 \%)$, and $1(1.7 \%)$, respectively. About $88.3 \%$ $(53 / 60)$ of isolates were obtained from wound culture specimens, $1(1.7 \%)$ from urine culture, $3(5 \%)$ from blood culture, and $3(5 \%)$ from endotracheal secretion culture. 


\section{Antibiotic resistance pattern}

According to disk diffusion results, all MRSA strains were resistant to clarithromycin and azithromycin. In addition, the majority of the strains was resistant to erythromycin $59(98.33 \%)$, clindamycin $56(93.3 \%)$, and trimethoprim/ sulfamethoxazole 58 (96.67\%), whereas, using the E-test, all MRSA isolates were susceptible to teicoplanin with a maximum range 0.25 ( $\mathrm{MIC} \leq 4 \mathrm{mg} / \mathrm{ml})$, linezolid = $0.19(\mathrm{MIC} \leq 4 \mathrm{mg} / \mathrm{ml})$, vancomycin $=0.5(\mathrm{MIC} \leq 2 \mathrm{mg} / \mathrm{ml})$, and tigecycline $=0.25$ ( $\mathrm{MIC} \leq 4 \mathrm{mg} / \mathrm{ml}$ ) and showed resistance to oxacillin (MIC $\geq 4 \mathrm{mg} / \mathrm{ml}$ ). Besides, the D-test results showed that $30(50 \%)$ of the MRSA isolates have the inducible clindamycin resistance phenotype. The resistance profile for all isolates to macrolides and other tested antibiotics is listed in Table II. Fifty-nine (98.3\%) isolates were simultaneously resistant to erythromycin, azithromycin, and clarithromycin (crossresistance); whereas only $1(1.7 \%)$ isolate had various macrolide susceptibility pattern. This isolate was susceptible to erythromycin and was resistant to azithromycin and clarithromycin. The highest antimicrobial resistance was related to wound specimens with $100 \%$ resistance to erythromycin, clarithromycin, and azithromycin and $93.3 \%$ resistance to clindamycin.

\section{MDR profiles}

The results of the susceptibility testing showed that all 60 MRSA isolates were resistant to at least two antibiotics, and the majority of isolates $(N=58$, 96.6\%) was multidrug-resistant (MDR) with five diverse patterns (Table III).

Table II. Prevalence of resistance to the tested antibiotics among MRSA isolates using the disk diffusion and $t$-test methods

\begin{tabular}{lccc}
\hline Antibiotics & Resistant no. (\%) & Intermediate no. (\%) & Susceptible no. (\%) \\
\hline Erythromycin & $59(98.33)$ & 0 & $1(1.67)$ \\
Clarithromycin & $60(100)$ & 0 & 0 \\
Azithromycin & $60(100)$ & 0 & 0 \\
Vancomycin & 0 & 0 & $60(100)$ \\
Clindamycin & $56(93.3)$ & 0 & $4(6.67)$ \\
Linezolid & 0 & 0 & $60(100)$ \\
Teicoplanin & 0 & 0 & $60(100)$ \\
Trimethoprim/sulfamethoxazole & $58(96.67)$ & 0 & $2(3.33)$ \\
Quinupristin/dalfopristin & 0 & 0 & $60(100)$ \\
Tigecycline & 0 & 0 & $60(100)$ \\
Rifampin & $9(15)$ & 0 & $51(85)$ \\
Gentamicin & $40(66.6)$ & 0 & $20(33.3)$ \\
\hline
\end{tabular}

Note: MRSA: methicillin-resistant Staphylococcus aureus. 
Table III. Multidrug-resistant profiles of methicillin-resistant Staphylococcus aureus isolates

\begin{tabular}{llc}
\hline Multidrug-resistant profile & \multicolumn{1}{c}{ Phenotypic resistance } & Number of isolates (\%) \\
\hline I & ERY-CLR-AZM-SXT & $2(3.3)$ \\
II & ERY-CLR-AZM-CLI-SXT & $16(26.6)$ \\
III & ERY-CLR-AZM-CLI-SXT-GEN & $30(50.0)$ \\
IV & ERY-CLR-AZM-CLI-SXT-RIF-GEN & $9(15.0)$ \\
V & CLR-AZM-CLI-SXT-GEN & $1(1.6)$ \\
\hline
\end{tabular}

Note: ERY: erythromycin; CLR: clarithromycin; AZM: azithromycin; CLI: clindamycin; SXT: trimethoprim-sulfamethoxazole; RIF: rifampicin; GEN: gentamicin.

Most isolates (50\%) had an antibiotic resistance profile of number III (erythromycinclarithromycin-azithromycin-clindamycin-trimethoprim-sulfamethoxazolegentamicin).

$P C R$

MRSA isolates were screened for the presence of ermB, ermA, ermC, and msrA genes as the main causative agents of resistance to macrolides. The frequency rates of $m s r A$, ermA, and ermC genes in MRSA isolates were $23(38.3 \%), 28(46.7 \%)$, and $22(36.7 \%)$, respectively. In addition, 32 (53.3\%) MRSA isolates harbored at least one of the four investigated genes. Seventeen (28.3\%) macrolide-resistant MRSA harbored ermA, msrA, and ermC genes simultaneously.

In contrast, the ermB gene was absent in all MRSA isolates. All (100\%) $m s r A$-, erm $A$-, and erm $C$-positive isolates were resistant to clarithromycin, azithromycin, and erythromycin and $98.33 \%$ of clindamycin-resistant isolates harbored genes of ermA and msrA. Statistical analyses showed that among the MRSA isolates, difference in prevalence of ermA, ermC, and $m s r A$ genes was significant in clarithromycin- and clindamycin-resistant MRSA isolates.

\section{Discussion}

S. aureus remains a major cause of wound infection in patients with burn injuries [17]. Infection by MRSA has been observed to be higher than $50 \%$ in burn units. The increase in antibiotic resistance of this pathogen involved in wound infections is a great therapeutic problem and worsens the prognosis of burn patients [18]. The high frequency of infections caused by MRSA and its diverse antimicrobial resistance patterns had led to the use of MLSB antibiotics in the 
treatment of these infections [19]. At present, the widespread use of these antibiotics in treatment of infections caused by $S$. aureus has led to the emergence of MLSB-resistant strains [19, 20].

In this study, $79 \%$ of the isolated $S$. aureus strains was identified as MRSA by the application of the cefoxitin disk and oxacillin-salt agar screening, which is comparable to the $77.9 \%$ prevalence of MRSA in Iranian burn patients [21]. In a study from capital of Iran, Abbasian et al. [22] reported prevalence rate of $64.2 \%$ for MRSA in a burn hospital. The prevalence rate of MRSA in Iranian burn centers is different in various regions. However, several studies revealed the increasing prevalence of MRSA in our country [21]. These inconsistencies in the prevalence of MRSA among various regions might be due to the different antibiotic use patterns and dissimilar infection control strategies [22].

In this study, according to results of disk diffusion testing, most of the MRSA isolates showed high resistance rate to macrolide antibiotics including $100 \%$ resistance against clarithromycin and azithromycin and $98.3 \%$ against erythromycin, respectively. In a previous study performed by Seifi et al. [23], lower resistance rate $(88.6 \%)$ was reported for erythromycin in clinical isolates of MRSA. In this study, similar to the previous report by Goudarzi et al. [14], the majority of the erythromycin-resistant isolates had cross-resistance to other macrolides. This study revealed a high level of resistance to clindamycin (93.3\%) that was similar to the study from a regional burn center in Southeastern China [24]. Furthermore, this study indicated that more than $90 \%$ of MRSA isolates were MDR (resistance to three or more unique antimicrobial drug classes), which were in accordance with the results of another investigation from Iran carried out by Goudarzi et al. [25].

Moreover, our finding revealed that the vancomycin, linezolid, teicoplanin, and tigecycline were the most effective antibiotics against MRSA that was parallel with the findings reported by Amissah et al. [1] and Ohadian Moghadam et al. [26]. Therefore, the mentioned antibiotics can still be used for treatment of the infections caused by MRSA in burn patients in our region. In contrast to another report from Iran [25], our results showed low frequency of resistance to quinupristin/dalfopristin (10\%) and rifampicin (15\%) in MRSA isolates that is probably due to the low prescribing of these antibiotics in our region.

In this study, the molecular assay identified the ermA gene as the most frequent (46.7\%) resistance gene in the MRSA strains isolated from burn patients. In addition, none of the MRSA isolates had the ermB gene that was in line with the report by Lina et al. [27]. These findings were in disagreement with the study by Fasihi et al. [28] performed in Kerman, Iran, in which an incidence of $11 \%$ and $3.5 \%$ was reported for ermA and ermB genes, respectively. It has been reported 
that the prevalence of the ermB in staphylococci isolated from animal sources is higher than those isolated from human specimens [29].

Furthermore, the erm and msr genes have been reported in Denmark, the United Kingdom, and Tunisia. In Tunisia and Denmark, ermB and erm $A$ genes were the most common clindamycin- and erythromycin-resistant genes, respectively, but in this study, erm $C$ was the most common [28]. In this study, according to the results of PCR, the prevalence of erm $C$ gene was lower than that of the erm $A$ and $m s r A$ genes, whereas most studies report erm $C$ as the most frequent genetic determinant [30, 31]. Regarding $m s r A$, we found the incidence rate of $38.3 \%$ in MRSA isolates. In a study from Serbia, the $m s r A$ was the most common resistance gene [32].

The dissimilarities in the prevalence rate of MLSB resistance genes in different studies may be explained by the heterogeneous nature of erythromycin resistance, or it may be due to the loss of small plasmids that carry erm and $m s r$ genes [28]. We identified the erm $A+m s r A+\operatorname{erm} C$ gene combinations in $28.3 \%$ of the MRSA isolates. Similarly, the simultaneous presence of two or more MLSB resistance genes has been reported in previous studies from different countries [33, 34].

\section{Conclusions}

This study has investigated the frequency of MLSB resistance genes in MRSA strains isolated from burn patients using PCR method. This was the first study to investigate the frequency of these genes in MRSA isolated from burn patients in our region, which demonstrated the erm $A$ gene as the most common MLSB resistance gene among erythromycin-resistant isolates.

Because of the high prevalence of macrolide and lincosamide resistance found in MRSA isolates from infections of burn patients in Ahvaz, Iran, a knowledge about susceptibility patterns may provide crucial information for controlling the dissemination of antimicrobial resistance and it is recommended that local periodic survey be performed.

\section{Acknowledgements}

The authors would like to thank the Department of Microbiology, Faculty of Medicine, Ahvaz Jundishapur University of Medical Sciences for their cooperation. They would also like to appreciate the Vice Chancellor for Research affairs, Ahvaz Jundishapur University of Medical Sciences, Ahvaz, Iran, and Tropical and 
Infectious Diseases Research Center of the University for their financial (grant no. 91126) and executive support. FS and EAM contributed equally to this work.

\section{Conflict of Interest}

The authors declare no competing interests.

\section{References}

1. Amissah, N. A., van Dam, L., Ablordey, A., Ampomah, O. W., Prah, I., Tetteh, C. S., van der Werf, T. S., Friedrich, A. W., Rossen, J. W., van Dijl, J. M., Stienstra, Y.: Epidemiology of Staphylococcus aureus in a burn unit of a tertiary care center in Ghana. PLoS One 12, e0181072 (2017).

2. Emaneini, M., Bigverdi, R., Kalantar, D., Soroush, S., Jabalameli, F., Khoshgnab, B. N., Asadollahi, P., Taherikalani, M.: Distribution of genes encoding tetracycline resistance and aminoglycoside modifying enzymes in Staphylococcus aureus strains isolated from a burn center. Ann Burns Fire Disasters 26, 76-80 (2013).

3. Kooistra-Smid, M., Nieuwenhuis, M., Van Belkum, A., Verbrugh, H.: The role of nasal carriage in Staphylococcus aureus burn wound colonization. FEMS Immunol Med Microbiol 57, 1-3 (2009).

4. Alebachew, T., Yismaw, G., Derabe, A., Sisay, Z.: Staphylococcus aureus burn wound infection among patients attending Yekatit 12 hospital burn unit, Addis Ababa, Ethiopia. Ethiop J Health Sci 22, 209-213 (2012)

5. Boucher, H. W., Corey, G. R.: Epidemiology of methicillin-resistant Staphylococcus aureus. Clin Infect Dis 46, 344-349 (2008).

6. Coutinho, V. D., Paiva, R. M., Reiter, K. C., de-Paris, F., Barth, A. L., Machado, A. B.: Distribution of erm genes and low prevalence of inducible resistance to clindamycin among staphylococci isolates. Braz J Infect Dis 14, 564-568 (2010).

7. Zarifian, A., Setayesh, Y., Askari, E., Amini, A., Rahbar, M., Naderinasab, M.: Inducible clindamycin resistant Staphylococcus aureus in Iran: A systematic review and metaanalysis. J Med Microbiol 4, 43-52 (2015)

8. Moosavian, M., Shoja, S., Rostami, S., Torabipour, M., Farshadzadeh, Z.: Inducible clindamycin resistance in clinical isolates of Staphylococcus aureus due to erm genes, Iran. Iran J Microbiol 6, 421-427 (2014).

9. Gherardi, G., De Florio, L., Lorino, G., Fico, L., Dicuonzo, G.: Macrolide resistance genotypes and phenotypes among erythromycin-resistant clinical isolates of Staphylococcus aureus and coagulase-negative staphylococci, Italy. FEMS Immunol Med Microbiol 55, 62-67 (2009).

10. Adhikari, R. P., Shrestha, S., Barakoti, A., Amatya, R.: Inducible clindamycin and methicillin resistant Staphylococcus aureus in a tertiary care hospital, Kathmandu, Nepal. BMC Infect Dis 17, 483-487 (2017).

11. Lall, M., Sahni, A. K.: Prevalence of inducible clindamycin resistance in Staphylococcus aureus isolated from clinical samples. Med J Armed Forces India 70, $43-47$ (2014). 
12. Burch, M. L., Ballinger, M. L., Yang, S. N., Getachew, R., Itman, C., Loveland, K., Osman, N., Little, P. J.: Thrombin stimulation of proteoglycan synthesis in vascular smooth muscle is mediated by protease-activated receptor- 1 transactivation of the transforming growth factor $\beta$-type I receptor. J Biol Chem 285, 26798-26805 (2010).

13. Clinical and Laboratory Standards Institute (CLSI): Methods for Dilution Antimicrobial Susceptibility Tests for Bacteria That Grow Aerobically. CLSI document M7-A4. CLSI, Wayne, PA, 2018.

14. Goudarzi, G., Tahmasbi, F., Anbari, K., Ghafarzadeh, M.: Distribution of genes encoding resistance to macrolides among staphylococci isolated from the nasal cavity of hospital employees in Khorramabad, Iran. Iran Red Crescent Med J 18, e25701 (2016).

15. Aktas, Z., Aridogan, A., Kayacan, C. B., Aydin, D.: Resistance to macrolide, lincosamide and streptogramin antibiotics in staphylococci isolated in Istanbul, Turkey. J Microbiol 45, 286-290 (2007).

16. Martineau, F., Picard, F. J., Grenier, L., Roy, P. H., Ouellette, M., Bergeron, M. G.: Multiplex PCR assays for the detection of clinically relevant antibiotic resistance genes in staphylococci isolated from patients infected after cardiac surgery. The ESPRIT Trial. J Antimicrob Chemoth 46, 527-534 (2000).

17. Norbury, W., Herndon, D. N., Tanksley, J., Jeschke, M. G., Finnerty, C. C.: Infection in burns. Surg Infect 17, 250-255 (2016).

18. Mehmood Khan, T., Leng Kok, Y., Bukhsh, A., Lee, L. H., Chan, K. G., Goh, B. H.: Incidence of methicillin resistant Staphylococcus aureus (MRSA) in burn intensive care unit: A systematic review. Germs 8, 113-125 (2018).

19. Shantala, G. B., Adithi, S. S., Rahul, R. K., Nagarathnamma, T.: Detection of inducible clindamycin resistance in clinical isolates of Staphylococcus aureus by the disc diffusion induction test. J Clin Diagn Res 5, 35-37 (2011).

20. Foster, T. J.: Antibiotic resistance in Staphylococcus aureus. Current status and future prospects. FEMS Microbiol Rev 41, 430-449 (2017).

21. Emaneini, M., Beigverdi, R., van Leeuwen, W. B., Rahdar, H., Karami-Zarandi, M., Hosseinkhani, F., Jabalameli, F.: Prevalence of methicillin-resistant Staphylococcus aureus isolated from burn patients in Iran: A systematic review and meta-analysis. J Glob Antimicrob Resist 12, 202-206 (2018).

22. Abbasian, S., Farahani, N. N., Mir, Z., Alinejad, F., Haeili, M., Dahmardehei, M., Mirzaii, M., Khoramrooz, S. S., Nasiri, M. J., Darban-Sarokhalil, D.: Genotypic characterization of Staphylococcus aureus isolated from a burn centre by using agr, spa and SCCmec typing methods. New Microbes New Infect 26, 15-19 (2018).

23. Seifi, N., Kahani, N., Askari, E., Mahdipour, S., Naderi, N. M.: Inducible clindamycin resistance in Staphylococcus aureus isolates recovered from Mashhad, Iran. Iran J Microbiol 4, 82-86 (2012).

24. Chen, K., Lin, S., Li, P., Song, Q., Luo, D., Liu, T., Zeng, L., Zhang, W.: Characterization of Staphylococcus aureus isolated from patients with burns in a regional burn center, Southeastern China. BMC Infect Dis 18, 51 (2018).

25. Goudarzi, H., Seyedjavadi, S. S., Udo, E. E., Beiranvand, E., Fazeli, M., Goudarzi, M.: Molecular characterization and distribution of class 1 integron-bearing methicillin resistant Staphylococcus aureus strains in burn patients, Tehran, Iran, Jundishapur. J Microbiol 10, e40592 (2017). 
26. Ohadian Moghadam, S., Pourmand, M. R., Aminharati, F.: Biofilm formation and antimicrobial resistance in methicillin-resistant Staphylococcus aureus isolated from burn patients, Iran. J Infect Dev Ctries 8, 1511-1517 (2014).

27. Lina, G., Quaglia, A., Reverdy, M. E., Leclercq, R., Vandenesch, F., Etienne, J.: Distribution of genes encoding resistance to macrolides, lincosamides, and streptogramins among staphylococci. Antimicrob Agents Chemother 43, 1062-1066 (1999).

28. Fasihi, Y., Saffari, F., Kandehkar Ghahraman, M. R., Kalantar-Neyestanaki, D.: Molecular detection of macrolide and lincosamide-resistance genes in clinical methicillin-resistant Staphylococcus aureus isolates from Kerman, Iran. Arch Pediatr Infect Dis 5, e37761 (2017).

29. Argudín, M. A., Tenhagen, B. A., Fetsch, A., Sachsenröder, J., Käsbohrer, A., Schroeter, A., Hammerl, J. A., Hertwig, S., Helmuth, R., Bräunig, J., Mendoza, M. C.: Virulence and resistance determinants in German Staphylococcus aureus ST398 isolates from non-human origin. Appl Environ Microbiol 77, 3052-3060 (2011).

30. Piatkowska, E., Piatkowska, J., Przondo-Mordarska, A.: The strongest resistance of Staphylococcus aureus to erythromycin is caused by decreasing uptake of the antibiotic into the cells. Cell Mol Biol Lett 17, 633-645 (2012).

31. Ogbolu, D. O., Alli, O. A., Oluremi, A. S., Onifade, C. O.: Erythromycin resistance determinants in clinical Gram positive cocci isolated from Nigerian patients. J Clin Diagn Res 12, 5-10 (2018).

32. Mišić, M., Čukić, J., Vidanović, D., Šekler, M., Matić, S., Vukašinović, M., Baskić, D.: Prevalence of genotypes that determine resistance of staphylococci to macrolides and lincosamides in Serbia. Front Public Health 28, 200 (2017).

33. Faccone, D., Togneri, A. M., Podesta, L., Perez, M., Gagetti, P., Sanchez, S., Romero, G., Corso, A.: MRSA pediatric clone expressing ermC plus lnuA genes causing nosocomial transmission and healthcare workers colonization in a neonatal intensive care unit. Infect Genet Evol 25, 78-80 (2014).

34. Cetin, E. S., Gunes, H., Kaya, S., Aridogan, B. C., Demirci, M.: Distribution of genes encoding resistance to macrolides, lincosamides and streptogramins among clinical staphylococcal isolates in a Turkish university hospital. J Microbiol Immunol Infect 43, 524-529 (2010). 